\title{
Isolation and Identification of Symbiont Microorganisms from Bioluminescent Marine Life
}

\author{
Delianis Pringgenies $^{1^{*}}$, Kartika Dewi $^{1}$ and Pramita Apriliyani ${ }^{1}$ \\ ${ }^{1}$ Department of Marine Sciences, Faculty of Fishery and Marine Sciences, Diponegoro University, \\ Indonesia.
}

Authors' contributions

This work was carried out in collaboration among all authors. Author DP as the first author is a project coordinator, Author KD as second author contribute as fish expert and Author PA as squid expert. All authors read and approve the final manuscript.

Article Information

DOI: $10.9734 / A R R B / 2019 / v 33 i 230118$

Editor(s):

(1) Dr. Saleha Sadeeqa, Head of Pharmacy Practice Department, Institute of Pharmacy, Lahore College for Women University,

Reviewers:

(1) Esra Ersoy Omeroglu, Ege University, Turkey.

(2) Debarshi Kar Mahapatra, Dadasaheb Balpande College of Pharmacy, India.

(3) Asib SAAD, Tishreen University, Syria.

Complete Peer review History: https://sdiarticle4.com/review-history/51717

Original Research Article

Received 30 July 2019

Accepted 05 October 2019

Published 19 October 2019

\begin{abstract}
Bioluminescence means the ability of animals or plants to naturally produce light. The three known ways by which bioluminescence is produced are through specific cells called photocytes, bioluminescent glands in tissues and symbiotic bioluminescent microorganisms. Bioluminescence in Loligo duvaucelii is known to be caused by the presence of symbiotic microorganisms in bioluminescent sacs. There is a need to compile more information on bioluminescent symbiotic microorganisms on marine life in Indonesia and their potential. This study aims to determine the species of bioluminescent microorganisms on squid and fish, namely Loligo sp. and Loligo edulis from the waters of Jepara and the Bombay duck (Harpadon nehereus) from the Strait of Malacca, Indonesia and their potential. The samples were collected by isolating the microorganisms from the luminescent organs, after which the bioluminescent microorganisms were used in the research. This research consisted of antimicrobial tests against pathogenic microorganisms which were conducted qualitatively. The bioluminescent microorganisms were identified using biochemical assay and molecular assay (16S rRNA PCR). Tests results from Loligo sp. symbiotic microorganisms found
\end{abstract}


two isolates which showed antimicrobial activities against pathogenic Multi Drug Resistant (MDR) microorganisms, namely uncultured bacterium clone 1P-1-G05 against Escherichia coli with 32.59 $\mathrm{mm}$ of inhibitory zone and Uncultured bacterium clone $3 \mathrm{~g} 10 \mathrm{a}$ against Enterobacter sp. with 28.44 $\mathrm{mm}$ of inhibitory zone. The bioluminescent symbiont microorganisms in Loligo edulis, which was identified to be Photobacterium phosphoreum, showed antimicrobial activities against Vibrio harveyi, E. coli, Staphylococcus aureus, and Bacillus sp. Bioluminescent symbiotic microorganisms on $\mathrm{H}$. nehereus identified Alteromonas macleodii, which showed gamma hemolysis on the blood agar test.

Keywords: Bioluminescent microorganisms; gamma hemolysis; Loligo sp.; Ioligo edulis; H. nehereus; MDR microorganisms.

\section{INTRODUCTION}

Bioluminescence is the most important source of light in deep sea ecosystems. Resulted from the oxidation of substrate catalyzed by enzymes, it enables living organism to radiate light [1]. The emission of light that occurs benefits the organism because it is useful for foraging, avoiding predators, identification or communication with others, and for camouflage [2]. Bioluminescence in Loligo duvaucelii species is due to the presence of symbiont microorganisms in its bioluminescence organ [3]. Luminescent microorganisms have genes which allow them to produce luciferase enzymes and long aldehyde chains needed in bioluminescence chemical reactions [4]. This symbiosis is mutualistic because bioluminescent organisms get a variety of benefits from the light emitted, while microorganisms obtain a protected environment rich in nutrients [5].

In general, the reaction that causes the phenomenon of bioluminescence is influenced by two chemicals, namely luciferin and luciferase or photoprotein. Luciferin is a compound that can produce light [6]. Some organisms can produce luciferin compounds themselves, while some others get them from other organisms. External luciferin is obtained from food or through a symbiotic relationship. In addition to luciferin, the chemical that contributes to the phenomenon of bioluminescence is luciferase. Luciferase is an enzyme that interacts with the substrate to influence the rate of chemical reactions. The bioluminescence reaction requires the luciferase enzyme to catalyze three substrates, namely reduced flavin mononucleotide $\left(\mathrm{FMNH}_{2}\right)$, oxygen $\left(\mathrm{O}_{2}\right)$, and long chain aldehyde $(\mathrm{R}-\mathrm{COH})$. This reaction will free flavin (FMN), long chain fatty acids (R-COOH), water molecules $(\mathrm{H} 2 \mathrm{O})$, and accompanied by visible light (hv) emission [7]. The bioluminescence phenomenon occurs because of certain different chemical reactions in every animal. In this chemical reaction, luciferin acts as a substrate that helps bind oxygen to organic molecules. The interaction of luciferin oxidized by luciferase forms a by-product in the form of highenergy molecules. This molecule is referred to as oxyluciferin. The reaction then releases light energy which gives a luminescent appearance on the animal.

Most of the biota have living bioluminescence in the sea. Of the 700 genera of biota with bioluminescence in nature, $80 \%$ of them are in the ocean [8]. In the vast ocean with various types of microorganisms, bioluminescence organs that are rich in nutrients certainly become ideal ecosystems for microorganisms, resulting in competition among the luminescent microbial communities. In addition to the ability to produce light to win in this competition, bioluminescence microorganism have the ability to protect hosts from pathogenic microorganisms. These properties allow the use of luminescent microbial isolates genes in the field of ecology as heavy metal biosensor agents in the aquatic environment [9]. Therefore, the potential of bioluminescence studies is very promising in the field of biotechnology and ecology. The source of the study can be obtained from bioluminescence organisms found in Indonesian waters as a source of potential luminescent microbial isolates. Indonesian waters are vast, with various types of marine organisms, including bioluminescence organisms, such as Anomalops katoptron from Banda Island [10] and Loligo duvaucelii from Jepara [3].

Therefore, this study aims to determine the species of bioluminescent organism on squid and fish, namely Loligo sp. and Loligo edulis from the waters of Jepara and the Bombay duck $(H$. nehereus) from the Strait of Malacca, Indonesia and their potential. 


\section{METHODOLOGY}

\subsection{Sampling and Isolation of Luminescent Microorganisms Squids}

Five squids were collected by catching using floating net mesh from 1-2 $\mathrm{m}$ depth from the waters of Jepara. The samples were kept in a cool box for further preparation in the laboratory. Isolation of luminescent microorganisms was performed by pulverizing the light organ of the squid, after which a $10^{-5}$ dilution was made. The microbial suspension was then spread onto Zobell 2216E media composed of $2.5 \mathrm{~g}$ of peptone, $0.5 \mathrm{~g}$ of yeast extract, and $15 \mathrm{~g}$ of agar per liter. The microbial culture was then incubated for 2 days in room temperature. The resulting microbial colonies were isolated. The colonies producing the most luminescence were purified to obtain purified culture.

Determination of luminescent symbiotic microbial isolates in squid light organs was based on the morphology of the luminescence bacterial colonies grown on Nutrient Agar (NA) media in petri dishes as well as observing the emission of light by bacteria in a dark room. The resulting isolates were purified to obtain purified isolates of luminescent microorganisms. The observation for the morphology of the luminescence bacterial colony includes color, shape, surface and the edge of the colony and biochemical identification.

\subsection{Sampling and Isolation of Luminescent Microorganisms on The Bombay Duck (H. nehereus)}

Twenty Bombay duck fish samples, each approximately $23 \mathrm{~cm}$ in length, were collected from Tanjung Balai Karimun Island, Riau Islands, Indonesia. The collected samples were stored in a cool box prior to laboratory preparation. The samples were rinsed with sterilized saline water and were put in the open on a room temperature. After 8 hours of dark room observation, luminescent microorganisms occurred on the surface of the body. One gram of skin tissue from the samples was sampled for serial dilution. The resulting microbial suspension was then spread onto Zobell $2216 \mathrm{E}$ media composed of $2.5 \mathrm{~g}$ of peptone, $0.5 \mathrm{~g}$ of yeast extract, and $15 \mathrm{~g}$ of agar per liter. The microbial culture was then incubated for $2 \times 24$ hours in room temperature. Single purified colony with the most luminescence was inoculated into a new medium for molecular identification and hemolysis test.

\subsection{Identification of Organism}

Characterization of microorganisms were performed through TCBS (Thiosulfate-citrate-bile salts-sucrose) isolation, Oxidase test, Indole test, Oxidative fermentative (Sucrose and Lactose) test, Motility test, $\mathrm{H}_{2} \mathrm{~S}$ test, and Voges-Proskauer test. Gram staining was also performed according to standard method. Molecular analysis was performed in accordance to the following stages.

\subsection{Amplification of 16S Partial Ribosomes from Isolated Luminescent Microorganisms}

Genomic DNA from luminous bacterial microbial isolate was used as a template for PCR amplification. Amplification of $16 \mathrm{~S}$ ribosomal RNA (rRNA) was performed using 27f (5'AGAGTTT- GATCMTGGCTCAG-3') and 1492r (5'TACGGYTACCTTGTTACGACTT- 3') primers. Amplification took place in a thermal cycler with 30 rounds followed by denaturation of DNA at $94^{\circ} \mathrm{C}$ for 1 minute, at $55^{\circ} \mathrm{C}$ for primary annealing for 1 minute, and extension at $72^{\circ} \mathrm{C}$ for 1 minute. The final extension was carried out at $72^{\circ} \mathrm{C}$ for 10 minutes. PCR products were analyzed using gel electrophoresis (1\%) and the resulting images were analyzed using UVI Doc HD5 (UVITEC Cambridge).

The sequencing process was carried out at Genetika Science Inc., Indonesia. The result of the sequencing was the nucleotide of the $16 \mathrm{~S}$ rRNA gene region data, which was then processed and edited using BioEdit software, and was submitted to the $\mathrm{NCBI}$ database that stores information on nucleotide sequences. The phylogenetic tree was made using Blast tool software and designed by NCBI database search tool.

\subsection{Antimicrobial Activities of Luminous Microorganisms from Loligo sp}

This process is carried out by an overlay method [11]. Purified culture of bioluminescence organism isolated from Loligo $s p$. was used against Multi Drug Resistant (MDR) pathogenic organism of the species Klebsiella $s p$., Enterobacter sp. 5, Enterobacter sp. 10, Coagulase Negative Staphylococcus (CNS), Pseudomonas sp., and Escherichia coli. Pathogenic organism samples were obtained from Dr. Kariadi Central General Hospital, 
Semarang. MDR microorganisms were introduced in liquid Zobell 2216E plain media and then incubated for 24 hours at room temperature while being spun at $90 \mathrm{rpm}$. $1 \mathrm{~mL}$ of MDR microbial suspension was taken and put into 100 $\mathrm{mL}$ soft Zobell $2216 \mathrm{E}$ plain agar (1\% of total volume), after which it was introduced to Zobell 2216E saline solid media which had been cultured with luminescent microbial isolates from the squid sample, then incubated at room temperature for 1- 2 days. The bacterial isolates which formed inhibition zones were sorted and were put into another iteration. Isolates which still showed viable result after iteration were taken and stored for further analysis. Quantitative tests using paper disks were then performed. Antimicrobial tests were carried out by streaking microorganisms isolate onto the paper disk with $20 \mu \mathrm{L}$ concentration. The resulting inhibition zone was then measured with a caliper.

\subsection{Antimicrobial Activities of Luminous Microorganisms from Loligo sp}

This process was performed using agar diffusion method according to Kirby-Bauer [12]. This test was performed both qualitatively and quantitatively using NA media. Purified culture of bioluminescence microorganisms isolated from Loligo edulis was used against vibriosis-causing pathogenic bacteria in animals, $V$. harveyi and $V$. alginolyticus, and pathogens which cause various types of infections in humans, E. coli, S. aureus and Bacillus $s p$. The qualitative test was performed first to determine whether the luminescent microorganisms isolate has the ability to inhibit the growth of the pathogenic microorganisms. Antimicrobial tests were carried out by streaking microorganisms isolate onto the paper disk with $20 \mu \mathrm{L}$ concentration. The standard of microbial turbidity is equivalent to 0.5 McFarland. Pathogenic microorganisms sample was inoculated into NA media, after which paper disk was placed in the middle of the medium and was incubated for $4 \times 24$ hours at room temperature. The qualitative test result is a positive if transparent zone was formed around the paper disk. Otherwise, the test result is considered negative. Isolates showing positive result were put into quantitative testing. Quantitative test is performed to determine the diameter of inhibition zone. Quantitative test method is the same as the method used in qualitative tests. The formation of the barrier zone diameter was measured for each incubation period of 24 hours, 48 hours, 72 hours, and 96 hours using a caliper.

\subsection{Hemolytic Activity of Luminous Microorganisms Isolated from $H$. nehereus}

Blood agar is a differential media enriched with $5 \%$ human blood. This medium is used to determine the pathogenic properties of microorganisms. The test was performed by inoculating the luminous microorganisms isolated from $H$. nehereus into blood agar, and incubated in room temperature form 48 hours. After the observation period expired, observation was made for changes in coloration which indicate the ability of the microorganisms to destroy blood cells. Hemolysis alpha occurs when the agar surrounding the colony changes color into green or brown hue. Beta hemolysis indicated by the appearance of clear colors surrounding the colonies, whereas gamma hemolysis is indicated by no change in agar [13].

\section{RESULTS AND DISCUSSION}

\subsection{Luminescent Microorganisms from Loligo sp.}

Isolation of symbiont microorganisms of light organs from Loligo $s p$. resulted in 40 microbial isolates. After light emission observation, 2 microbial isolates were found to produce the most luminescence. Isolation results of microorganisms in Loligo sp light organ are presented in Fig. 1.

\subsection{Luminescent Microorganisms from Loligo edulis}

Isolation of symbiont microorganisms of light organs from Loligo edulis resulted in 1 microbial isolate. Determination of luminescent symbiotic microbial isolates in the light organ of Loligo edulis was based on the morphology of the luminescence bacterial colonies grown on Nutrient Agar (NA) media in petri dishes as well as observing the emission of light by bacteria in a dark room. The light produced was bluish in hue (Fig. 2). The resulting isolates were purified to obtain purified isolates of luminescent microorganisms. The microbial colony was milk white in color, with circular shape, convex surface, and even margin.

\subsection{Luminescent Microorganisms from the Bombay Duck $(H$. nehereus)}

Light emission from microorganisms obtained from the first serial dilution from the Bombay duck ( $H$. nehereus) (Fig. 3). The dilution result 
was introduced into agar media and the suspension was incubated for 48 hours. Based on the levels of light emitted, four colonies were selected to be purified. The purification resulted in one isolate which retained its capability in producing light (Fig. 4).

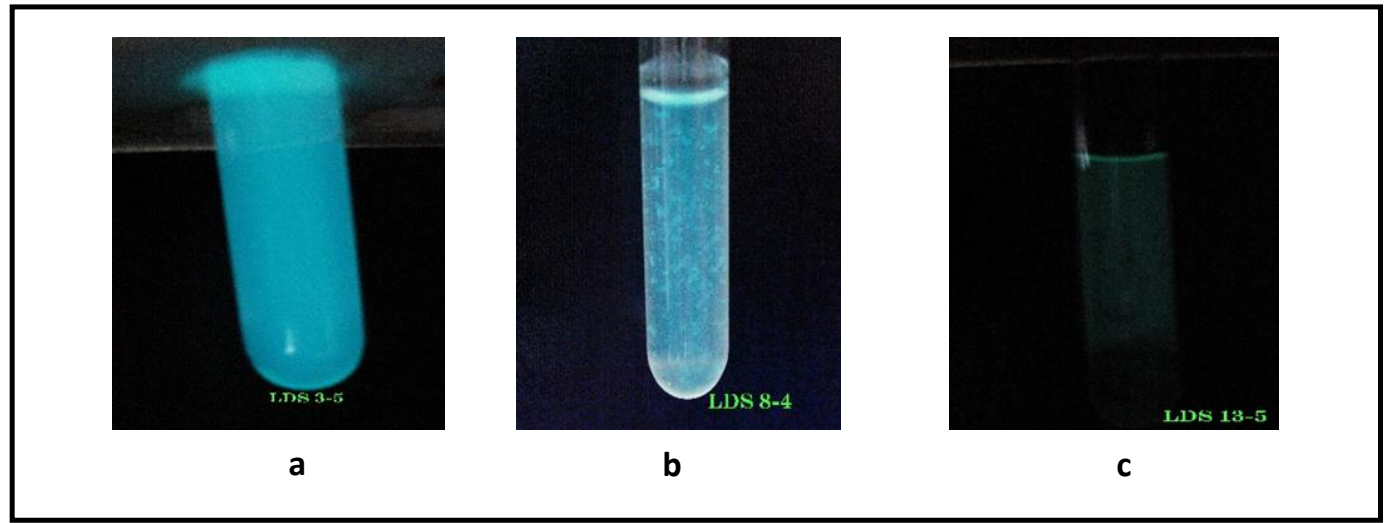

Fig. 1. Levels of light emitted by microbial isolates; (a) high, (b) medium, (c) low

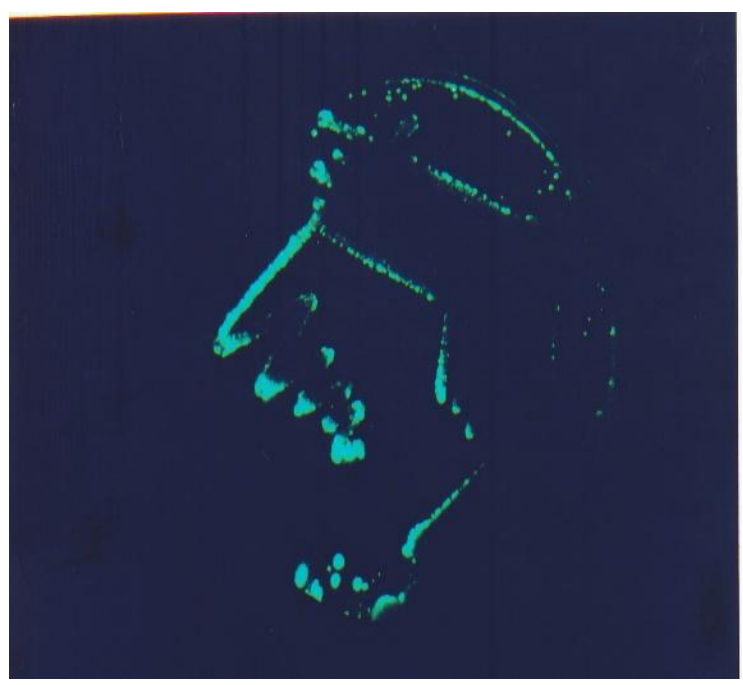

Fig. 2. Light emitted by the microbial isolate on NA media in a dark room



a 


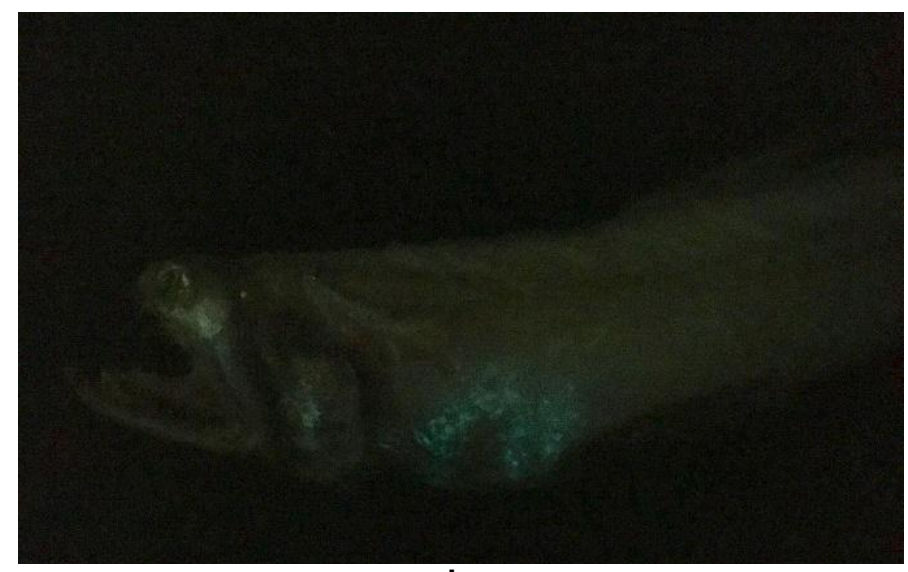

b

Fig. 3. Host of luminescent microorganisms (a) fresh Bombay duck (b) light-emitting Bombay duck

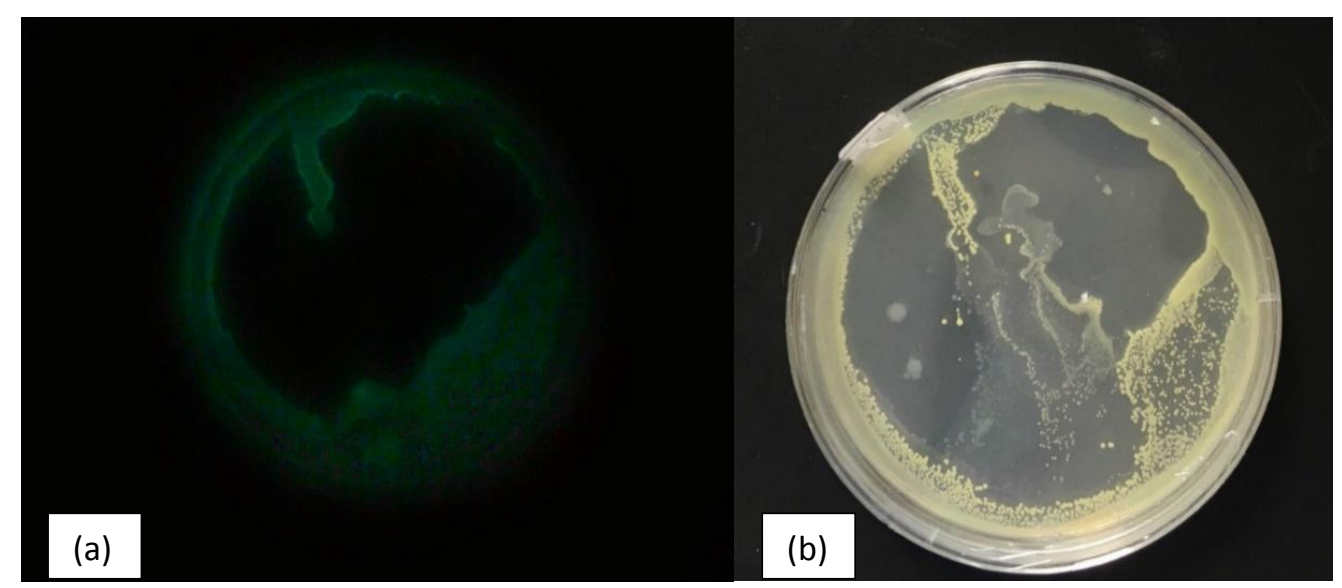

Fig. 4. Microbial isolate obtained from the Bombay duck (a) in a dark room (b) in a room with lighting

The luminescent microorganisms isolated from the Bombay duck was capable of emitting light in petri dish in the same way that it had done in its host (Fig. 4). Bioluminescence from the microbial isolate was obtained after 48 hours of incubation in room temperature. The light emission lasted for a period of 8 hours. The microorganisms was unstable in nature, which means that its bioluminescent property only occurred in the primary isolation. The microorganisms lost its ability to produce light after culture iteration from the isolate which had lost its bioluminescent property.

\subsection{Molecular Identification of Luminous Microorganisms from Loligo sp.}

The results of PCR 16S rDNA DNA amplification from 2 isolates obtained from Loligo $\mathrm{sp}$. are presented in Fig. 5.

The results of sequencing of LDS $12-4$ and LDS 18-5 are as follows:

LDS 12-4 (765R)

CGACGGTTGGGTTTAAAGACCAAAGAGTCGC CTTCGCCACTGGTGTTCCTCCACATCTCTAC GCATTTCACCGCTACACGTGGAATTCCACTC TCCTCTTCTGTACTCAAGTCCTCCAGTTTCCA ATGGCCCTCCACGGTTAAGCCGTGGGCTTTC ACATCAGACTTAAAG

LDS 18-5 (765R)

CCCGTCGTTCGACAGAGAGTCGCCTTCGCC ACTGGTGTTCCTCCACATCTCTACGCATTTCA CCGCTACACGTGGAATTCCACTCTCCTCTTC 
TGTACTCAAGTCCTCCAGTTTCCAATAGGCC CTCCACGGTTAAGCCGTGGGCTTTCACATCA GACTTAAAGGACCGCCTGCGCGCGCGCTTT ACGCCGAATAATTCCGGACAACGCTTGCCCC CTACGTATTACCGCGGGTGCTGGCAGGTAGT TAGCCGGGGCTTTCTGGTCAGGTACCGTCAA GGTGCCGCCGTATTCGAACGGCACTTGTTCT TCCCTGACAACAAAGTTTTACAATCCAAAAAC CTTCATCACTCACGCGGCGTTGCTCCGTCAA ACTTTCGTCCATTGCGAAAATTCCCTACTGCT GCCTCCGGAAGGAGTCGGGGCCGGGTCTCA TTCCCAGGGGGGCCAATCACCGTCTCAGGT CGGCTACCCATCGTCCCCTTGGTAA

Homology analysis using BLAST is presented in Fig. 6. And Fig. 7.

Search results of each microbial isolate sequence using BLAST and phylogenetic tree. The phylogenetic tree is used to determine closest relative of the sample microbial isolate with homology. The search results are presented in Table 1.

The results of identification with the BLAST database indicate that LDS 12-4 has the closest homology of $98 \%$ with uncultured bacterium clone 1P-1-G05 and LDS 18-5 having the closest homology of $95 \%$ with uncultured bacterium clone $3 \mathrm{~g} 10 \mathrm{a}$. The two isolates had the highest similarity levels of $98 \%$ and $95 \%$ respectively with microbial clones. The two clones were the result of a metagenomic study, in which both were derived from a mixture of DNA extracts isolated from nature and had not been isolated as pure extracts.

\subsection{Identification of Luminous Microbial Isolate from Loligo edulis using Biochemical Assay}

Luminescence bacterial isolates of the $L$. edulis ( $\mathrm{L} 2$ isolate) were then identified based on the methods in [14,15], which involved observations of morphology and biochemical properties of bacteria. The biochemical assay results are presented in Table 2.

The biochemical assay determined that L2 isolate is gram negative, is light emitting in dark spaces, do not grow in TCBS test medium, produces oxidase, does not produce indole, is oxidative towards carbohydrate (sucrose and lactose), is motile, does not produce $\mathrm{H} 2 \mathrm{~S}$ during growth in SIM medium and can ferment 2,3butanediol. The results of morphological observation on the luminescent microorganisms in $L$. edulis matche that of the characteristics of P. phosphoreum. Based on Bergey's Manual of Systematic Bacteriology, the following is the taxonomical classification data of $P$. phosphoreum:

Division: Protophyta

Class: Schizomycetes

Order: Eubacteriales

Family: Vibrionaceae

Genus: Photobacterium

Species: P. phosphoreum

\subsection{Molecular Identification of Luminous Microbial Isolate from $H$. nehereus}

One microbial isolate was obtained from the Bombay duck, based on its capability to producelight. The genetic information of the luminous microorganisms was successfully amplified using PCR (Fig. 8). The isolate identification was conducted using 16S rDNA gene. The result of identification showed that the luminous microorganisms showed 99\% match with Alteromonas macleodii strain NBRC 102226. The construction of the phylogenetic tree was then analyzed using BLAST homology (Fig. 9).

Identification of luminescent symbiont microorganisms of marine animals capable of emitting light in Indonesian waters are summarized in Table 3.

\subsection{Molecular Identification of Luminous Microbial Isolate from $H$. nehereus}

Antimicrobial activity test were conducted on the two isolates against MDR microorganisms Escherichia coli and Enterobacter sp. 5, Enterobacter sp. 10, Coagulase Negative Staphylococcus (CNS), Klebsiella sp., and Pseudomonas sp. Antimicrobial activity test results are presented in Table 4 and Table 5.

Table 1. Molecular identification of luminescent microorganisms isolates from Loligo sp.

\begin{tabular}{lllll}
\hline No. & Isolate & Identification Result & Homology (\%) & Access Ni. \\
\hline 1. & LDS 12-4 & Uncultured bacterium clone 1P-1-G05 & 98 & EU704793.1 \\
2. & LDS 18-5 & Uncultured bacterium clone 3g10a & 95 & EU873764.1 \\
\hline
\end{tabular}




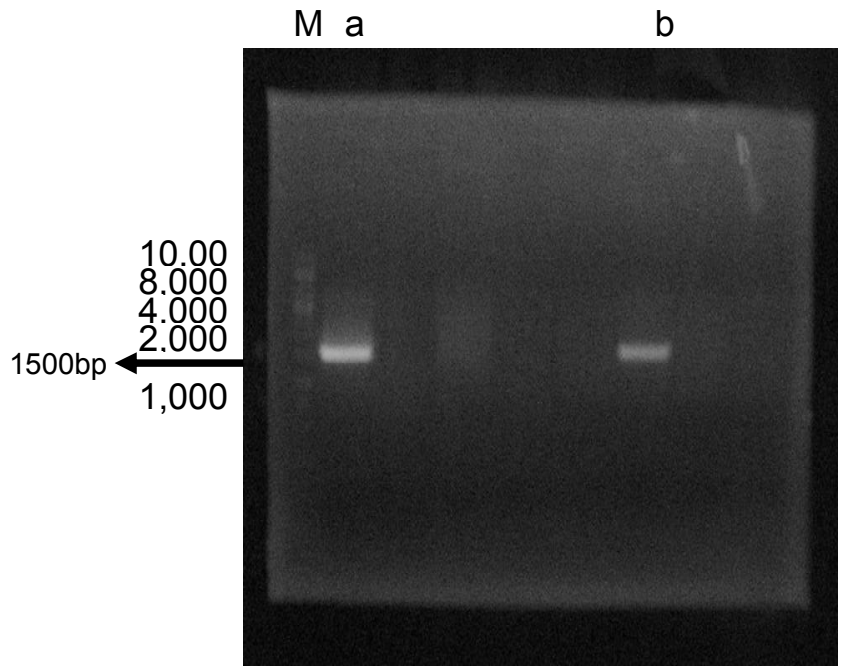

Fig. 5. The result of PCR $16 S$ rDNA DNA amplification of (a) isolat LDS 18-5, (b) LDS 12-4, and M : Marker 1500 bp

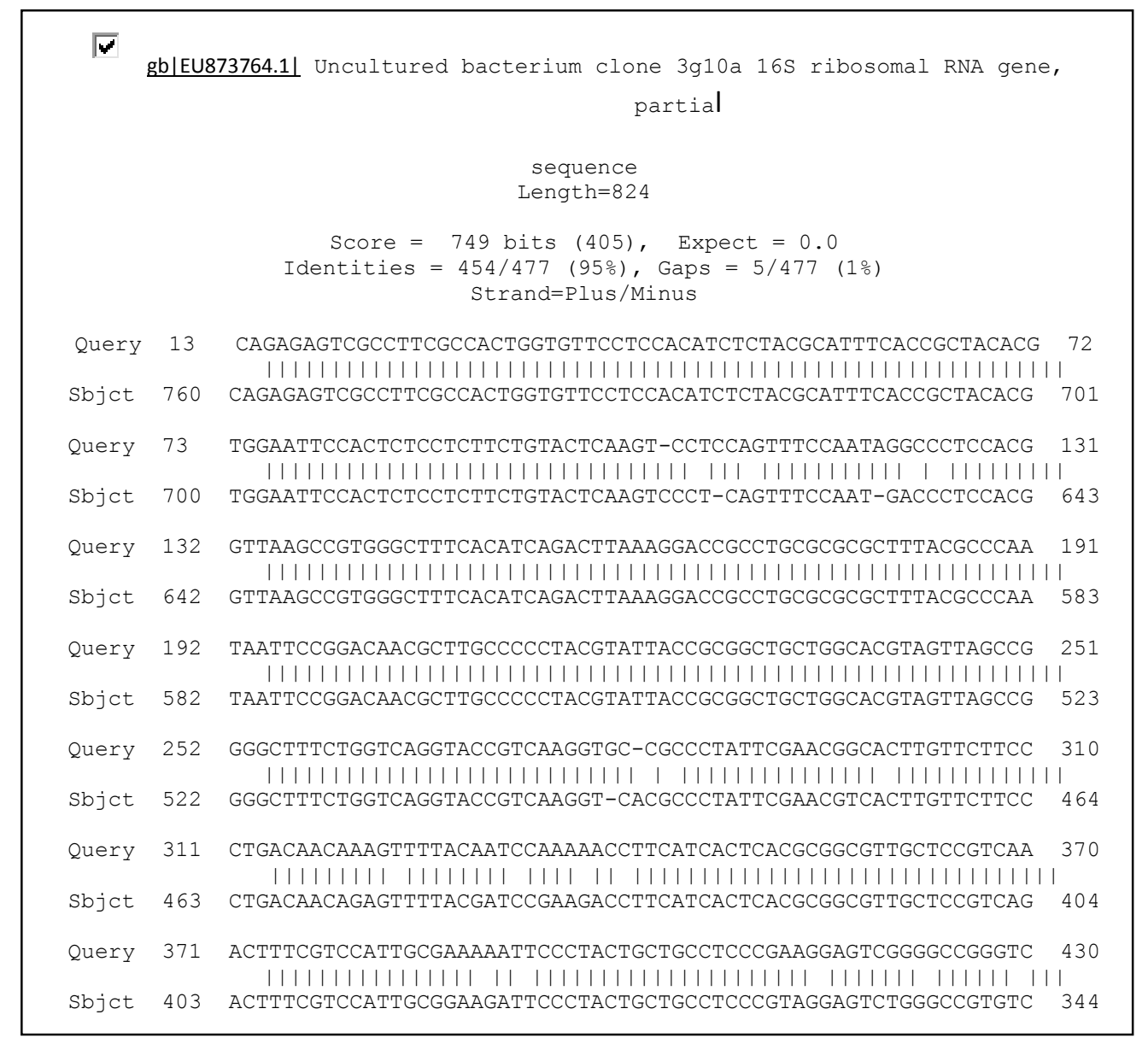

Fig. 6. Homology of isolate LDS 18-5 sequence using BLAST database. Symbol | indicates identical nucleotide 
Table 2. Results of biochemical assay of luminescent microorganisms obtained from the light organ of $L$. edulis

\begin{tabular}{ll}
\hline Biochemical Tests & Isolate L2 \\
\hline Gram Staining & - \\
Luminescent & + \\
TCBS & - \\
Oxidase & + \\
Oxidative Fermentative Test & - \\
Sucrose & - \\
Lactose & + \\
Motility & - \\
$\mathrm{H}_{2} \mathrm{~S}$ & + \\
Voges-Proskauer Test $\quad$ Note: Positive (+): Reaction occurred, Negative (-): No reaction occurred
\end{tabular}

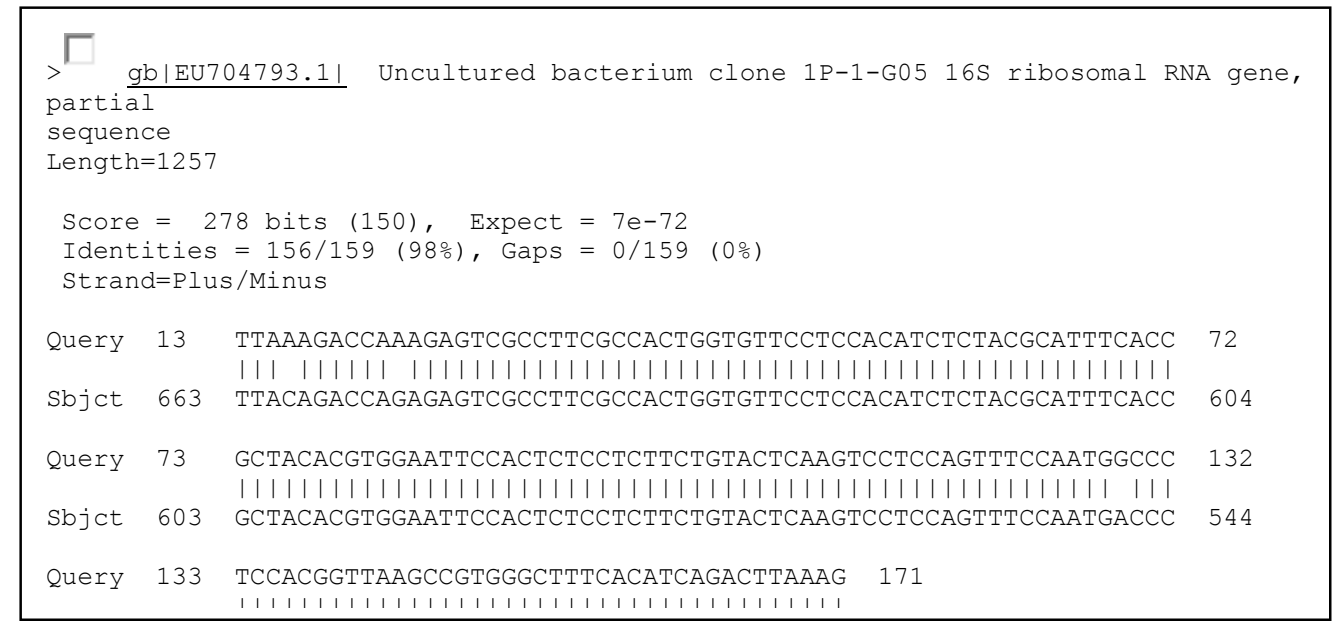

Fig. 7. Homology of isolate LDS 12-4 sequence using BLAST database. Symbol |: indicates identical nucleotide

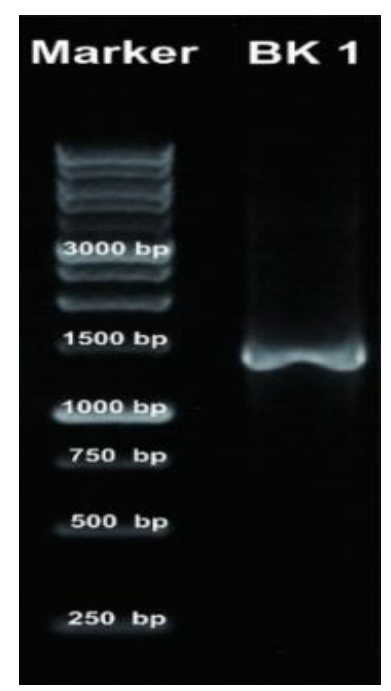

Fig. 8. Visualization of $P C R$ product using electrophoresis with $0.8 \%$ agarose 


\subsection{Antimicrobial Activities of Luminous Microorganisms from Loligo sp}

The sensitivity test of luminescent microbial isolate on the growth of pathogenic microorganisms showed that $\mathrm{L} 2$ bacterial isolate was bioactive or capable in inhibiting the growth of test microorganisms. This research uses $V$. harveyi, V. alginolyticus, E. coli, S. aureus and Bacillus sp. as test pathogens.

The qualitative test result of isolate L2 against the test pathogens ( $V$. harveyi, $V$. alginolyticus, E. coli, S. aureus and Bacillus sp.) are presented in Table 6.

The qualitative test of $\mathrm{L} 2$ isolates resulted in positive (+) against $V$. harveyi, E. coli, $S$. aureus and Bacillus sp., whereas against $V$. alginolyticus the result was negative (-) (Table 6). This means that L2 isolates are able to inhibit the growth of $V$. harveyi, E. coli, S. aureus and Bacillus sp. but it is not that of $V$. alginolyticus.

The quantitative sensitivity test result of isolate L2 against the test pathogens ( $\mathrm{V}$. harveyi, $\mathrm{V}$. alginolyticus, E. coli, S. aureus and Bacillus sp.) are presented in Table 7.

\subsection{Hemolysis Activity}

Hemolysis activity is determined based on testing results in blood agar. Lumious microorganisms isolated from the Bombay duck ( $H$. nehereus) showed hemolysis gamma with no change of color surrounding the growing colony on the blood agar. This shows that the microorganisms do not produce toxic substances capable of breaking down blood cells (Fig. 11).

Table 3. Isolated Bioluminescent Microorganisms

\begin{tabular}{|c|c|c|c|c|c|}
\hline $\begin{array}{l}\text { Strain } \\
\text { code }\end{array}$ & Source & $\begin{array}{l}\text { Sampling } \\
\text { location }\end{array}$ & Species & Method & $\begin{array}{l}\text { Luminescence } \\
\text { properties }\end{array}$ \\
\hline LDS 12-4 & Squid (Loligo sp.) & $\begin{array}{l}\text { Waters of } \\
\text { Semarang }\end{array}$ & $\begin{array}{l}\text { Uncultured } \\
\text { bacterium clone } \\
\text { 1P-1-G05 }\end{array}$ & Molecular & Positive \\
\hline LDS 18-5 & Squid (Loligo sp.) & $\begin{array}{l}\text { Waters of } \\
\text { Semarang }\end{array}$ & $\begin{array}{l}\text { Uncultured } \\
\text { bacterium clone } \\
3 \mathrm{~g} 10 \mathrm{a}\end{array}$ & Molecular & Positive \\
\hline L2 & $\begin{array}{l}\text { Squid (Loligo } \\
\text { edulis) }\end{array}$ & $\begin{array}{l}\text { Awur Bay, } \\
\text { Jepara }\end{array}$ & $\begin{array}{l}\text { Photobacterium } \\
\text { phosphoreum }\end{array}$ & $\begin{array}{l}\text { Biochemical } \\
\text { (Bergey's } \\
\text { Manual of } \\
\text { Systematic } \\
\text { Bacteriology) }\end{array}$ & Positive \\
\hline BK & $\begin{array}{l}\text { The Bombay } \\
\text { duck ( } H \text {. } \\
\text { nehereus) }\end{array}$ & $\begin{array}{l}\text { Waters of } \\
\text { Tanjung } \\
\text { Balai } \\
\text { Karimun, } \\
\text { Riau } \\
\text { Islands }\end{array}$ & $\begin{array}{l}\text { Alteromonas } \\
\text { macleodii }\end{array}$ & Molecular & Positive \\
\hline
\end{tabular}

Table 4. Inhibition Zone of luminous microorganisms from Loligo sp. against MDR pathogens

\begin{tabular}{llllllll}
\hline No. & $\begin{array}{l}\text { Loligo } \\
\text { sp. }\end{array}$ & \multicolumn{6}{c}{ Antimicrobial activity against MDR microorganisms (mm) } \\
\cline { 3 - 7 } & E. coli & $\begin{array}{l}\text { Enterobact } \\
\text { er sp. 5 }\end{array}$ & $\begin{array}{l}\text { Enterobacter } \\
\text { sp. 10 }\end{array}$ & CNS & Klebsiella & Pseudomonas \\
sp. & sp. \\
\hline 1 & LDS 12-4 & + & - & - & - & - & - \\
2 & LDS 18-5 & - & + & - & - & - & - \\
\hline \multicolumn{7}{c}{ Note:+: Inhibition zone formed; -: Inhibition zone not formed }
\end{tabular}

Table 5. Antimicrobial activity test results

\begin{tabular}{llc}
\hline MDR Pathogenic Microorganisms & LDS 12-4 & LDS 18-5 \\
\cline { 2 - 3 } & Inhibition zone diameter (mm) \\
\hline Escherichia coli & 32.59 & - \\
Enterobacter sp.5 & - & 28.44 \\
\hline
\end{tabular}




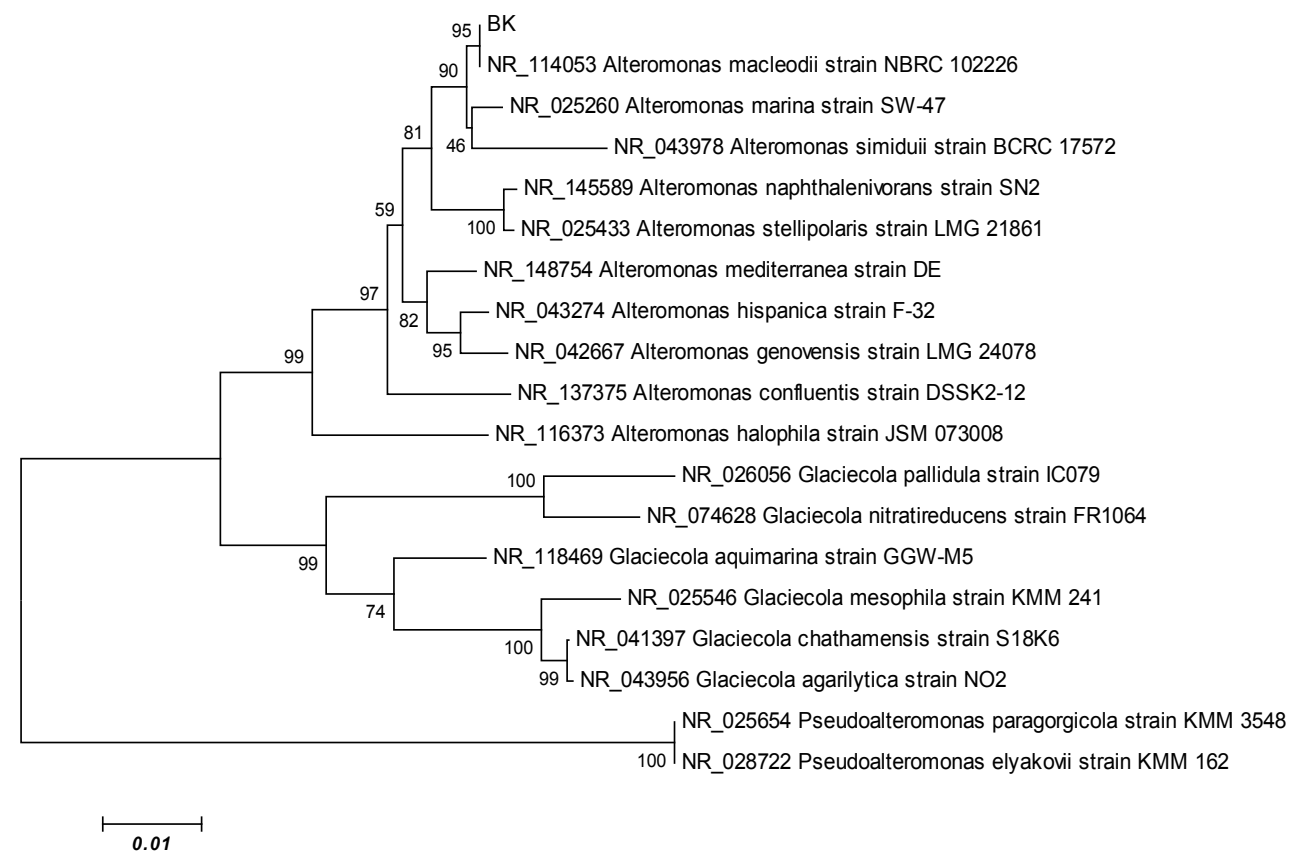

Fig. 9. The phylogenetic tree of the isolated microorganisms

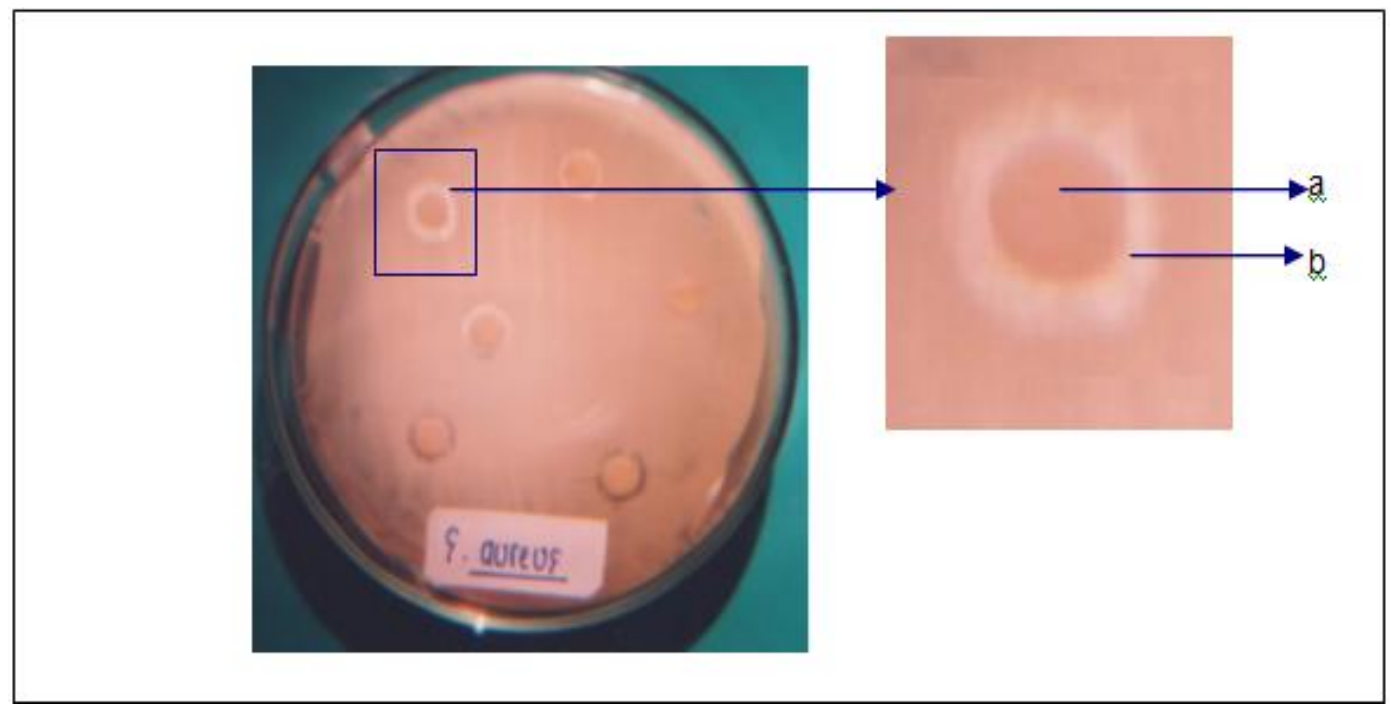

Fig. 10. Formation of inhibition zone diameter

Note:a: paper disk; b: inhibition zone

\subsection{Discussion}

Bioluminescence in marine animals can be produced through a photophore which inherent special cells called photocytes, or through glands [2], or can be produced by light organs of fish that are symbiotic with luminescent bacteria, Luminescent microorganisms naturally have genes which allow them to produce luciferase enzymes and long aldehyde chains needed in bioluminescence chemical reactions [4]. Luciferase in an enzyme responsible in catalyzing luciferin substrate, which results in visible light thorough bioluminescence chemical reaction. The chemical reaction of bioluminesce is as follows: 


$$
\begin{aligned}
\mathrm{FMNH}_{2}+\underset{+\mathrm{RCOO}}{\mathrm{RCOO}}+\mathrm{O}_{2} \longrightarrow \mathrm{hv}(490 \mathrm{~nm}) & \mathrm{FMN}+\mathrm{H}_{2} \mathrm{O}
\end{aligned}
$$

Luminescent bacteria isolated from Loligo $\mathrm{sp}$. produce blue colored luminescence in petri dishes, and luminescent bacteria isolated from Loligo edulis have strong blue luminescence. On the other hand, luminescent bacteria from $\mathrm{H}$. nehereus have weak green luminescence. The blue-green color has a wavelength range of approximately $490-509 \mathrm{~nm}$.

Luciferase isolated from various types of bacteria shows the maximum spectral range of bioluminescence around $490 \mathrm{~nm}$ to $509 \mathrm{~nm}$ which ranges in the blue-green range [16]. 470 $\mathrm{nm}$, which translates into the color blue, is the range of spectra for species for the genus Photobacterium [17]. Blue-green is a color that is often produced from bioluminescence chemical reactions because most marine organisms have the most sensitive visual pigments in the bluegreen region [18]. In addition to that, blue is the color with the farthest-reaching wavelength in sea water (Imax $475 \mathrm{~nm}$ ) [19]. Green is the next most common color and is more commonly found in benthic and shallow coastal species, perhaps due to an increase in turbidity from particles in the water that spread blue light and support the transmission of longer wavelengths [18].

Two luminescent microbial isolates from Loligo $\mathrm{sp}$. were identified as uncultured bacterium clone
1P-1-G05 and uncultured bacterium clone $3 \mathrm{~g} 10 \mathrm{a}$, while luminescent microbial isolate from Loligo edulis was identified as Photobacterium phosphoreum. Luminescent bacteria from $\mathrm{H}$. nehereus was identified as Alteromonas macleodii strain NBRC 102226. Luminescent bacteria isolated from Loligo sp. or Loligo edulis showed strong and stable luminescence, meaning they can be recultured. On the other hand luminescent microbial isolates from $\mathrm{H}$. nehereus displayed weak and unstable luminescence, meaning that they will lose their luminosity if they are cultured from darkened colonies. Luminescent microorganisms naturally possess a gene called the Lux operon, consisting of luxCDABEG. This Lux operon is responsible for the production of light in bacteria. The complex Lux operon system is a microbial mechanism for quorum sensing [20]. Quorum sensing is a form of communication between microbial cells to form density and in this case produce light. From this very complex bioluminescence system, it is thought that several factors are the reason that several strains of luminescent bacteria carry lux genes when isolated from their host or natural habitat but these microorganisms do not express lux genes, case in point is Vibrio cholerae [21], or when isolated from its host the luminescent microorganisms loses its natural phenotype making luminescence only occurs during the first isolation but becomes dark after being recultured [22].

Table 6. Qualitative test results of isolate L2 against test pathogens

\begin{tabular}{llllll}
\hline Isolate & \multicolumn{5}{c}{ Test Microorganisms } \\
\cline { 2 - 6 } Code & V. harveyi & V. alginolyticus & E. coli & S. aureus & Bacillus sp. \\
\hline L2 & + & - & Note:+: Inhibition zone formed; $-:$ Inhibition zone not formed & + \\
\hline \multicolumn{4}{c}{}
\end{tabular}

Table 7. Inhibition zone of luminescent microorganisms in L. edulis against pathogenic microorganisms

\begin{tabular}{lll}
\hline Pathogenic microorganisms & Incubation period (h) & Inhibition zone diameter (in $\mathbf{~ m m}$ ) \\
\hline V. harveyi & 24 & 8.87 \\
& 48 & 8.79 \\
E. coli & 24 & 8.31 \\
& 48 & 8.21 \\
S. aureus & 24 & 9.02 \\
& 48 & 9.07 \\
Bacillus sp & 24 & 9.01 \\
& 48 & 8.83 \\
\hline
\end{tabular}




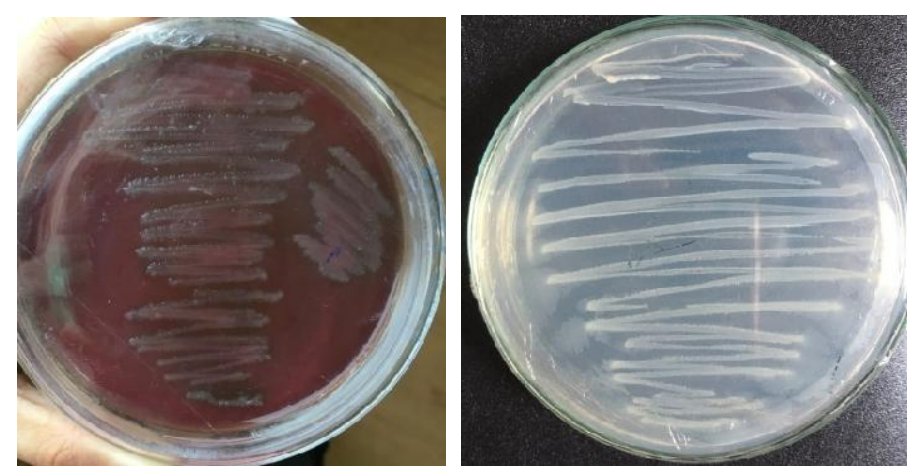

Fig. 11. (a) colony on blood agar (b) colony on Zobell agar

Luminescent microorganisms from the sea, both those living in symbiosis with light organs or living free, which have so far been mostly identified as Vibrio, Photobacterium and Alteromonas (shewanella) [23]. Exploration of luminescent microorganisms from various waters and bioluminescence organisms continues with so many reported new species that add to the list of luminescent microorganisms. Most of these species are identified as the genus Vibrio or Photobacterium. Four luminescent microorganisms isolated from the coastal region of Chah Bahar port, Sea of Oman, were identified as new strains and were reported to GeneBank. The four species mentioned are Vibrio sp. Persian 1, Vibrio sp. Persian 2, Vibrio sp. Persian 3, and Vibrio sp. Persian 4 [24]. Isolation of luminescent bacteria from squid taken from Malaysian waters was identified as Photobacterium leiognathi, whereas free living luminescent microorganisms from these waters was identified as Vibrio sp. [25].

Symbion microorganisms have the potential to produce secondary metabolites to protect host organisms, as a defense against pathogenic microorganisms, and for the purposes of interspecies communication [26]. Some luminescent microorganisms are reported to have antimicrobial properties, although so far luminescent microorganisms have not been explored as new potential for sources of antimicrobial agents for sources of antimicrobial agents for emerging global threats of multi drug resistant microorganisms [27].

Isolate from Loligo sp. was identified as Uncultured bacterium clone 1P-1-G05 with antimicrobial potential against $E$. coli MDR pathogenic microorganisms, which was capable of forming $32.59 \mathrm{~mm}$ inhibition zone, whereas the luminescent microorganisms identified as
Uncultured bacterium clone $3 \mathrm{~g} 10 \mathrm{a}$ which displayed antimicrobial properties against Enterobacter sp.5 MDR pathogenic microorganisms and formed $28.44 \mathrm{~mm}$ of inhibition zone. The luminescent microorganisms Photobacterium phosphoreum isolated from $L$. edulis showed antibacterial properties against $\mathrm{V}$. harveyi, E. coli, S. aureus, and Bacillus sp. Several luminescent microorganisms have also been reported to show antimicrobial properties; [26] reported 7 species of luminous microorganisms $(V$. harveyi, $V$. campbellii, $V$. owensii, $V$. rotiferianus, $V$. alginolyticus, $P$. damselae and $P$. leiognathi) showing antimicrobial activity against one pathogenic bacterium with inhibition zones ranging from 7 to $25 \mathrm{~mm}$. [28] reported that luminescent bacteria were isolated from the mangrove ecosystem of Roach Park, Tuticorin, India, generally from the species Vibrio sp. and had antibacterial activity against human pathogenic microorganisms Escherichia coli, Staphylococcus aureus, and Bacillus subtilis. In addition, luminescent microorganisms isolated from Lagocephalus spadiceus (half-smooth golden puffer fish), Leiognathus equulus (ponyfish), Scomber japonicus (Pacific chub mackerel), and Lutjanus argentimaculatus (red snapper) were identified as Vibrio $s p$. (98\%), Vibrio anguillarium strain X0906 (96\%), Vibrio sp. (93\%), and uncultured bacterium clone F2G (89\%). The luminescent microorganisms also have the ability as antibacterial against MDR microorganisms $S$. aureus and K. pneumonia [27].

In general, the open surface area of marine organisms is rich in nutrients, giving rise to interest and competition among microbial communities [29]. This competition champions microorganisms that are able to produce metabolites that are beneficial for both the host and the microorganisms itself. It is known that 
luminescent microorganisms are symbiotic, and that they mostly live inside light-producing organs, such as those found in the light organs of Loligo sp. and L. edulis. The cum-squid light organ is only intended for certain types of luminescent microorganisms and is not a residence for non-luminescent microorganisms [4]. So that luminescent microorganisms in symbiosis with light organs no longer need to compete with other microorganisms that do not have luminous properties. However, this study found that luminescent microorganisms from Loligo sp. was able to inhibit the growth of MDR microbial pathogens and luminescent microorganisms L. written was able to inhibit the growth of various human pathogenic microorganisms. [26] states that this ability is obtained because of the compounds produced by these microorganisms are beneficial for their survival through intra and interspecies chemical communication.

Microbial isolate from $H$. nehereus shows hemolysis gamma with no discoloration around the growing colony on the blood agar media. This shows that the microorganisms do not produce toxic substances capable of breaking down blood cells. Hemolysis is indicated by discoloration surrounding the colony on blood agar. This test is conducted to categorize bacteria in pathogenic and non-pathogenic groups by looking at the ability of bacteria to break down blood cells. Hemolysis alpha is the ability of bacteria to break down a portion of red blood cells, which occurs when the surrounding colonies turn green or brownish. Beta hemolysis is indicated by the appearance of clear colors surrounding the colonies, whereas gamma hemolysis is indicated by no change in agar [13]. In the future, the isolates of luminescent bacteria can be explored further for the potential they have given that these microorganisms do not produce blood cell breaking toxins.

Bioluminescence microorganisms have yet been explored intensively as new, potential antibiotic sources. So that later research can be further developed for such uses and to discover more properties of the antimicrobial compounds produced by luminescent microorganisms. Luminescent microorganisms have been known to have many benefits in the field of biotechnology, so further research to study bacterial self-defense mechanisms and bacterial evolution so that they can fight various pathogenic microorganisms is viable.

\section{CONCLUSION}

Microbial isolation from light organ of Loligo $s p$. found two isolates emitting light with bluish hue. Isolate LDS 12-4 was identified as Uncultured bacterium clone 1P-1-G05 with antimicrobial potential against $E$. coli MDR pathogenic microorganisms, which was capable of forming $32.59 \mathrm{~mm}$ inhibition zone. Isolate LDS $18-5$ was identified as uncultured bacterium clone $3 \mathrm{~g} 10 \mathrm{a}$ which displayed antimicrobial properties against Enterobacter sp.5 MDR pathogenic microorganisms and formed $28.44 \mathrm{~mm}$ of inhibition zone. The analysis of luminescent microorganisms from $L$. edulis indicated the microorganisms was $P$. phosphoreum of which strong light emitted was bluish in hue. This species also showed strong antimicrobial properties against $V$. harveyi, E. coli, $S$. aureus, and Bacillus sp. The analysis of luminescent microorganisms from $H$. nehereus the Bombay duck was $A$. macleodii and this species was found to be capable of producing light with bright greenish hue. The microorganisms also displayed gamma hemolysis.

\section{COMPETING INTERESTS}

Authors have declared that no competing interests exist.

\section{REFERENCES}

1. Haddock SHD, Mark AM, James FC. Bioluminescence in the Sea. Annu. Rev. Mar. Sci. 2010;2:443-93.

DOI:10.1146/annurev-marine-120308081028.

2. Herring PJ. Luminescence in cephalopods and fish, Symp, Zool, Soc, London. 1977;38:127-159.

3. Pringgenies D, Jǿrgensen JM. Morphology of the luminous organ of squid Ioligo duvauceli d'Orbigny, 1839. Acta Zoologica. 1994;75(4):305-309.

4. Dunlap PV. Encyclopedia of Microbiology Bioluminescence, Microbial: Physiology. Elsevier Inc. University of Michigan, Ann Arbor; 2009.

5. Pringgenies D, Sastrodihardjo S, Nganro NR, Nyoman. Bacteria Symbiosis in Light Organ of the Squid Loligo duvauceli and cuttlefish Sepia sp Phuket Marine Biological Center, Thailand.Spec. No. $2001 ; 25(1): 145-148$. 
6. Pringgenies D, Sedjati S. Isolasi dan Determinasi Bakteri Luminesensi yang Bersimbiosis pada Cumi-cumi Loligo duvauceli. J. Ilmiah Pengembangan IImuilmu Kelautan. Indonesia. 2004;9(1):26-30.

7. Side DD, Giuffreda E, Tredici SM, Talà A, Pennetta C, Alifano P. Quorum sensing: Complexity in the bacterial world. Chaos, Solitons and Fractals. 2015;81:551-555.

8. Shimomura O. Bioluminescence: Chemical Principles and Methods. Singapore (SG): World Scientific Publishing; 2006.

9. Charrier T, Durand MJ, Affi M, Jouanneau S, Gezekel H, Thouand G. Bacterial Bioluminescent Biosensor Characterisation for On-line Monitoring of Heavy Metals Pollutions in Waste Water Treatment Plant Effluents. Biosensors, Pier Andrea Serra, IntechOpen; 2010.

DOI: $10.5772 / 7210$.

10. Hellinger J, JaÈgers $P$, Donner $M$, Sutt $F$, Mark MD, Senen B, Tollrian R, Herlitze S. The flashlight fish Aanomalops katoptron uses bioluminescent light to detect prey in the dark. Plos OneLoS ONE. 2017;12(2): 1-18.

11. Terkina IA, Parfenova VV, Ahn TS. Antagonistic activity of actinomycetes of Lake Baikal. Biochemistry and Microbiology. 2006;42:173-176.

12. Lay BW. Analisis Mikroba di Laboratorium. PT Rajagrafindo Persada, Jakarta. Indonesia; 1994.

13. Lesmana $M$, Subekti $D$, Simanjuntak $\mathrm{CH}$, Tjaniadi P, Campbell JR, Ofoyo BA. Vibrio parahaemolyticus associated with choleralike diarrhea among patients in North Jakarta, Indonesia. Diagnostic Microbiology and Infectious Disease. 2001;39(2):71-75.

14. Cowan ST, Steel KJ. Manual for the identification of medical bacteria. $3^{\text {rd }}$ Edition. New York: Cambridge University Press; 1993.

15. Taslihan A, Murdjani M, Pubomartono C, Kusnendar E. Bakteri pathogen penyebab penyakit mulut merah pada ikan kerapu tikus J Perikanan UGM, Indonesia. 2000;2(2):57-62.

16. Lee FJ. A glucose-repressible gene encodes acetyl-CoA hydrolase from Saccharomyces cerevisiae. J Biol Chem. 1990;265(13):7413-8.

17. Daubner SC, Astorga AM, Leisman GB, Baldwin TO. Yellow light emission of Vibrio fischeri strain Y-1: Purification and characterization of the energy-accepting yellow fluorescent protein. Proc Natl Acad Sci USA 84. 1987;8912-8916.

18. Herring PJ. Roy CM. The spectral characteristics of luminous marine organisms 220 Proc. R. Soc. Lond. B. 1983.

Available:https://doi.org/10.1098/rspb.1983 .0095.

19. Widder EA. Bioluminescence. In: Adaptive mechanisms in the ecology of vision. Edited by: S.N. Archer, M.B.A. Djamgoz, E. Loew, J.C. Partridge \& S. Vallerga. Kluwer Academic Publishers, Dordrecht, the Netherlands. 1999:555-581.

20. Bassler BL. Cell-to-cell communication in bacteria. Journal Cell. 2002;109:421-424.

21. Nealson $\mathrm{KH}$, Hastings JW. Bacterial bioluminescence: Its control and ecological significance. Microbiol Rev. 1979;43:496518.

22. Dunlap PV, Urbanczyk H. Luminous Bacteria in Prokaryotes. Springer-Verlag, Berlin. 2013:495-528.

23. Meighen EA, Szittner RB. Multiple repetitive elements and organization of the lux operons of luminescent terrestrial bacteria. Journal of bacteriology; 1992. DOI:10.1128/jb.174.16.5371-5381.1992.

24. Jabalameli L, Razavi MR, Hosseinkhani S, Akhavan SA. Isolation, identification and characterization of new luminous bacteria from Chah Bahar Port, southern marine habitat of Iran. Iranian Journal of Fisheries Sciences. 2015;14(3):555-566.

25. Yaser NA, Faiz MA, Foong A, Aslizah MZ, Iwana I. Isolation and identification of bioluminescent bacteria in squid and water of malaysia. Int'l Journal of Advances in Agricultural \& Environmental Engg. (IJAAEE). 2014;1(2):225-228.

26. Ramesh $\mathrm{CH}$, Mohanraju $\mathrm{R}$, Murthy $\mathrm{KN}$, Karthick P, Narayana S. Impact of light, temperature, salinity, and glycerol on the intensity of luminescence and growth of marine bioluminescent bacteria Vibro campbellii (strain SF1), Curr. Sci. 2014; 106:511-513.

27. Molina-Santiago C, Vicente A, Romero D. The race for antimicrobials in the multidrug resistance era. Microbial Biotechnology; 2017.

Available:https://doi.org/10.1111/17517915.12884

28. Arulmoorthy MP, Karunakaran K, Vignesh $\mathrm{R}$, Vasudevan $\mathrm{S}$, Srinivasan. Identification and antimicrobial potential of bioluminescent bacteria isolated from the 
mangrove ecosystem of the Roach Park, Tuticorin, South east coast of India. Bio Med Research. 2014;1(1):1-15.

29. Gram L, Jette M, Jesper BB. Antibacterial activity of marine culturable bacteria collected from a global sampling of ocean surface waters and surface swabs of marine organisms. Marine Biotechnology; 2009.

DOI:10.1007/s10126-009-9233-y.

(c) 2019 Pringgenies et al.; This is an Open Access article distributed under the terms of the Creative Commons Attribution License (http://creativecommons.org/licenses/by/4.0), which permits unrestricted use, distribution, and reproduction in any medium, provided the original work is properly cited.

Peer-review history:

The peer review history for this paper can be accessed here:

https://sdiarticle4.com/review-history/51717 